\title{
New strategies deliver solutions-oriented science
}

n November 2009, the new director of the USDA's National Institute of Food and Agriculture (NIFA) Roger Beachy posed a challenge to public and land-grant universities: "I want USDA science, extramural and intramural, to focus most of its resources on accomplishing a few, bold outcomes with great power to improve human health and protect our environment." He also added, "The scientific knowledge learned from these efforts must be translated into real solutions for real people."

Beachy's comments marked a new emphasis on competitive grants in agricultural research and the first installment in a plan for a significant increase in funding. Through its Agricultural and Food Research Initiative (AFRI), NIFA will disburse approximately \$262 million in competitive grants for the coming federal fiscal year; that amount could rise to $\$ 384$ million in the year to follow. The AFRI competitive grants program will address five challenges: childhood obesity, climate change, food safety, global food security and sustainable bioenergy.

Also last year, in April 2009, UC Vice President Dan Dooley and UC Regent Fred Ruiz endorsed the "ANR Strategic Vision 2025." The document states that UC ANR must focus and apply its strengths to people, programs and science-based solutions "to connect and deliver resources from the entire University of California, forming integrated teams to work on complex issues and develop multidisciplinary solutions."

These complementary calls for solutions-oriented science, outreach and education are both disruptive and exciting. In ANR, new groups of collaborators are creating 5-year plans driven by the first four strategic initiatives: sustainable food systems, endemic and invasive pests and diseases, sustainable ecosystems, and healthy families and communities (http://ucanr.org/sites/anrstaff/ Strategic_Initiatives).

For California Agriculture journal, these strategic shifts, along with upheavals in scholarly communication and the breakneck pace of technology, have spurred creativity, new collaborations and a renewed sense of the importance of reporting peer-reviewed, policy-relevant science integrated with the best practical information available.

In the world of scholarly communications, the same pressures are at work. Today, more than 3,000 disciplinary journals publish under some form of open-access model. California Agriculture and other land-grant publications have long been in the vanguard of open-access information, delivering original, peer-reviewed research to subscribers, virtually without charge. Increasingly, scientists also post articles in repositories such as the UC California Digital Library's eScholarship Repository, and use copyright alternatives to increase access, such as Creative Commons.

At the same time, journal consolidation and soaring prices for some scholarly journal subscriptions have intensified the struggle of public university libraries to maintain viable information resources (http://osc.universityofcalifornia. edu/news). Both open-access models and journal pricing controversies emphasize the importance of the freely available, peer-reviewed research found at California Agriculture Online, and

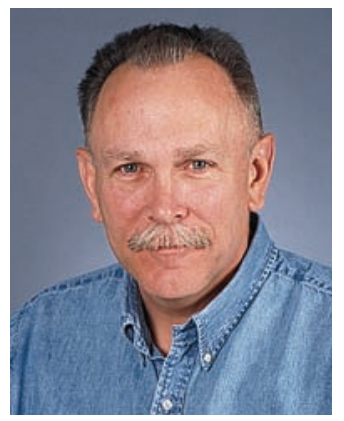

Robert W. Sams Director, UC ANR Communication Services and Information Technology the other communication tools that support ANR programs and make research accessible.

Recently, California Agriculture completely digitized and indexed the full text of its 64 years of publication. Collaborating with technology and communications colleagues in ANR Communication Services and Information Technology, the California Agriculture staff designed a more powerful and attractive search and display Web site to provide access to these resources (http:// californiaagricutlure.ucanr.org). The results have been remarkable. Launched in the last quarter of 2009, California Agriculture Online opened the entire publication database to researchers, agencies and the public, and also made it visible to general and scholarly search engines. The information is now easily discovered, searched and cited. As a result, California Agriculture Online generated over 13 million page views in 9 months.

This growth is not just evidence of the editorial and production quality we expect of California Agriculture journal. It is also evidence of the public's appetite for scientifically sound, accessible content. Additional efforts to digitize publications such as Hilgardia, and to enhance electronic publishing of ANR publications, are under way.

In a 2005 Society and Natural Resources article, Carr and Wilkinson noted, "For many years agricultural science assumed that research was done by scientists, repackaged by extension offices, and launched at farmers. Nowadays, their roles are converging and the boundaries are eroding." We, too, must increasingly create crosswalks between academic and extension publishing, and increase information dissemination.

The opportunity to bring these tools to bear on ANR's strategic vision and initiatives is exciting. The rapid collection and delivery of the best information available on emerging issues, and new ways to foster collaborative research and build science literacy, are within reach. Using these new tools while ANR restructures and adapts to major budget cuts, faces major funding challenges and competes for resources, is both sobering and motivating: sobering because critical resources have diminished due to decreased public support; and motivating because the opportunity to deploy powerful technologies enables us to support ANR academics - and to make a difference here and worldwide. 